\title{
IUI and Evidence-Based Medicine: An Urgent Need for Translation into Our Clinical Practice
}

\author{
Willem Ombelet
}

Intrauterine insemination (IUI) remains a widely used treatment option for many couples with unexplained infertility, cervical factor subfertility, physiological or psychological sexual dysfunction, mild endometriosis, and mild-to-moderate male subfertility. The rationale behind IUI is bypassing the cervical mucus barrier and increasing the gamete density at the site of fertilization. Despite the extensive literature on the subject of artificial insemination, controversy remains about the effectiveness of this very popular treatment procedure, particularly in relation to in vitro fertilization (IVF) and intracytoplasmic sperm injection [1].

To investigate the real value of IUI in unexplained and male subfertility cases, this treatment option has to be weighed against expectant management, medical and surgical treatment, timed coitus, IVF, and intracytoplasmic sperm injection. This comparison should not only involve success rates, but should also include a cost-benefit analysis, an analysis of the complication rates of the different treatment options, the invasiveness of the techniques, and couple compliance.

Contradictory results with IUI are observed because most studies are retrospective and vary in the comparison of the study groups, the use or nonuse of different ovarian hyperstimulation regimens, the number of inseminations per treatment cycle, the timing of ovulation, and methods of sperm preparation. Nevertheless, pregnancy rates of between 10 and $18 \%$ per cycle are reported [2-4].

\section{KARGER}

Fax + 41613061234

E-Mail karger@karger.ch

www.karger.com
(C) 2005 S. Karger AG, Basel

0378-7346/05/0591-0001\$22.00/0

Accessible online at:

www. karger.com/goi
Considering the effectiveness of IUI, Cohlen et al. [4] reported on the results of meta-analyses indicating the advantage of IUI versus timed intercourse during natural cycles in case of cervical factor subfertility, male factor subfertility, and unexplained infertility.

The use or nonuse of ovarian hyperstimulation is another important confounding factor, significantly influencing the success rate of IUI. The rationale behind the use of ovarian hyperstimulation in IUI is to increase the number of oocytes available for fertilization and to correct subtle unpredictable ovulatory dysfunction. Another advantage of superovulation with human menopausal gonadotropins or recombinant follicle-stimulating hormone is the enhanced opportunity for oocyte capture, fertilization, and implantation. On the other hand, the risks of ovarian hyperstimulation syndrome and especially multiple pregnancies are increased. The meta-analyses analyzed by Cohlen et al. [4] show the benefit of IUI with mild ovarian hyperstimulation $(\mathrm{MOH})$ versus timed intercourse with $\mathrm{MOH}$ in couples with male subfertility and unexplained subfertility. IUI with $\mathrm{MOH}$ was also more effective as compared with IUI during natural cycles in couples with unexplained subfertility. On the other hand, no difference in success rates could be observed in IUI with or without $\mathrm{MOH}$, if a moderate or severe male factor was involved.

Opponents of IUI draw our attention to the fact that the prediction of a multiple gestation is highly uncertain,

Willem Ombelet, MD, PhD

Genk Institute for Fertility Technology

Schiepse Bos 6

BE-3600 Genk (Belgium)

Tel.+3289325 754, E-Mail willem.ombelet@pandora.be 
especially when gonadotropins are used. Therefore, careful monitoring remains essential, and cancellation of the insemination procedure, rescue IVF, and follicular aspiration before ovulation are reasonable options when 3 or more follicles with a diameter $\geq 15 \mathrm{~mm}$ are present. Natural-cycle IUI should be offered more frequently, and, if necessary, ovulation induction can also be achieved with clomiphene citrate, a good first-line option, since ovulation can be induced in about $50-70 \%$ of the cases, with a multiple pregnancy rate of $6-8 \%[5,6]$. Gonadotropins are necessary in clomiphene-resistant cases and yield higher pregnancy rates as compared with clomiphene citrate, but at the expense of a higher proportion of multiple pregnancies ( $>15 \%$ in most reports) [7-9]. Low-dose step-up protocols with gonadotropins may decrease multiple birth rates significantly without influencing the ongoing pregnancy being tested.

Health care cost consciousness has become an integral part in the attitude of policy makers worldwide. Evidence related to the cost and effectiveness of infertility treatment exists, but most studies focus on IVF. Published data comparing the cost of IVF versus IUI are scarce, but recent studies from The Netherlands, the United Kingdom, and the United States indicate that initiating treatment with IUI appeared to be more cost-effective than
IVF in most cases of unexplained and moderate male subfertility [10-13]. Surprisingly and despite evidence-based arguments, most infertility centers are still neglecting the possibility of using IUI as a first-line treatment. Data from Australia and New Zealand clearly show that almost $80 \%$ of the centers are convinced of the cost-effectiveness of IUI, but nearly a third of the centers still promote IVF as a first-line treatment, even with patent tubes and normal semen. In case of male subfertility, IUI is rarely considered a first-line option [14].

Although IUI is a simple, noninvasive, and cheap firstline treatment in most subfertility cases, the future of IUI will depend on our ability to maintain the multiple pregnancy rate at an acceptable level, and this will undoubtedly be the most important challenge in the near future. We also have to convince infertility specialists to consider IUI as a first-line treatment option. If not, governments will make their own rules and recommendations, purely based on economic arguments.

It is clear that if the rate of multiple pregnancies after IUI is comparable or lower than that after IVF, IUI with or without ovarian hyperstimulation should be used for most subfertile couples and not only for couples on a waiting list for IVF.

\section{References}

1 Ombelet W, Bosmans E, Hinoul P, Nijs M: Pros and cons of IUI in male subfertility treatment. Reprod Biomed Online 2003;7(comp 1):66-72.

$>2$ Stone BA, Vargyas JM, Ringler GE, Stein AL, Marrs RP: Determinants of the outcome of intrauterine insemination: Analysis of outcomes of 9963 consecutive cycles. Am J Obstet Gynecol 1999;180(6 Pt 1):1522-1534.

$>3$ Kaplan PF, Austin DJ, Freund R: Subcutaneous human menopausal gonadotropin administration for controlled ovarian hyperstimulation with intrauterine insemination cycles. Am J Obstet Gynecol 2000;182:1421-1426.

4 Cohlen BJ, Vandekerckhove P, te Velde ER, Habbema JD: Timed intercourse versus intrauterine insemination with or without ovarian hyperstimulation for subfertility in men. Cochrane Database Syst Rev 2000;(2):CD000360.

$>5$ Sovino H, Sir-Petermann T, Devoto L: Clomiphene citrate and ovulation induction. Reprod Biomed Online 2002;4:303-310.
6 Ombelet W, Vandeput H, Van de Putte G, Cox A, Janssen M, Jacobs P, Bosmans E, Steeno O, Kruger T: Intrauterine insemination after ovarian stimulation with clomiphene citrate: Predictive potential of inseminating motile count and sperm morphology. Hum Reprod 1997;12: 1458-1463.

$>7$ Fauser BC, Van Heusden AM: Manipulation of human ovarian function: Physiological concepts and clinical consequences. Endocr Rev 1997;18:71-106.

$>8$ Guzick DS, Sullivan MW, Adamson GD, Cedars MI, Falk RJ, Peterson EP, Steinkampf MP: Efficacy of treatment for unexplained infertility. Fertil Steril 1998;70:207-213.

-9 Tur R, Barri PN, Coroleu B, Buxaderas R, Martinez F, Balasch J: Risk factors for highorder multiple implantation after ovarian stimulation with gonadotrophins: Evidence from a large series of 1,878 consecutive pregnancies in a single centre. Hum Reprod 2001;16:21242129.
Goverde AJ, McDonnell J, Vermeiden JP, Schats R, Rutten FF, Schoemaker J: Intrauterine insemination or in-vitro fertilisation in idiopathic subfertility and male subfertility: A randomized trial and cost-effectiveness analysis. Lancet 2000;355:13-18.

11 Karande VC, Korn A, Morris R, Rao R, Balin M, Rinehart J, Dohn K, Gleicher N: Prospective randomized trial comparing the outcome and cost of in vitro fertilization with that of a traditional treatment algorithm as first-line therapy for couples with infertility. Fertil Steril 1999;71:468-475.

12 Philips Z, Barraza-Llorens M, Posnett J: Evaluation of the relative cost-effectiveness of treatments for infertility in the UK. Hum Reprod 2000;15:95-106.

13 Van Voorhis BJ, Stovall DW, Allen BD, Syrop $\mathrm{CH}$ : Cost-effective treatment of the infertile couple. Fertil Steril 1998;70:995-1005.

14 Miskry T, Chapman M: The use of intrauterine insemination in Australia and New Zealand. Hum Reprod 2002;17:956-959. 